\title{
Cohort Study of Endodontic Therapy Success
}

\author{
Rosana Maria Coelho TRAVASSOS ${ }^{1}$ \\ Arnaldo de França CALDAS JUNIOR ${ }^{2}$ \\ Diana Santana de ALBUQUERQUE ${ }^{1}$ \\ ${ }^{1}$ Department of Endodontics, \\ ${ }^{2}$ Department of Dental Public Health, \\ Faculty of Dentistry, University of Pernambuco, Recife, PE, Brazil
}

\begin{abstract}
A retrospective cohort study was carried out aiming to assess the success rate of endodontic treatment of patients from the Faculty of Dentistry, University of Pernambuco, Brazil. The dental records of the sampling comprised all patients treated in 1998 and 1999 . Trials were standardized and a pilot study was carried out to determine the feasibility of the proposed study. Chi-square and Fisher's exact tests were used to calculate the level of significance that was set at 5\%. Logistic regression models were used to confirm significant effect of some variables on the endodontic outcome. The final sample size comprised $311(75.9 \%)$ women and $99(21.1 \%)$ men. The majority of cases $(82.9 \%)$ were considered successful. Success was less frequent for patients with up to primary school education $(55.6 \%)$ than for those with a higher degree of education (89.7\%). The vital condition of the pulp showed a statistically significant relationship with the success of endodontic therapy $(\mathrm{p}<0.05)$. These results suggest that it is possible to attain very high success rates for endodontic treatment when both the intraradicular and the extraradicular causes of failure of endodontic treatment are well managed.
\end{abstract}

Key Words: clinical and radiografic control, endodontic therapy.

\section{INTRODUCTION}

The goal of endodontic therapy is the prevention and/or the elimination of pathosis of endodontic origin. It is generally accepted that correct diagnosis, proper debridement and preparation of the pulp cavity, and subsequent complete obturation of the prepared cavity are the triad essential for successful root canal therapy (1).

Whenever the decision has to be made whether to perform endodontic treatment or to extract a tooth, it is of importance to gain an insight into the probability of success or failure under the given circumstances, i.e., age of the patient, socioeconomic class, vital or necrotic pulp, presence of periapical rarefaction, etc.

The literature is replete with studies evaluating the success rate of endodontic treatment and many follow-up studies have been performed. It is accepted that the success rate of treatment is positively correlated with the criteria for good technical quality of the root filling (2), the apical and coronal microleakage in endodontically treated teeth (3), persistence of microorganism in the apical root canal and presence of cysts (4), anatomy of the main canal (5), presence and extent of preoperative periapical pathosis (6), apical limit of filling (7), and presence of dental caries after root filling (8). Furthermore, variability in treatment outcome has been suggested to be due to variations in operators' adherence to adequate treatment procedures and techniques (9). Finally, in addition to root canal preparation and obturation, an appropriate treatment process includes, at the very least: preoperative radiography, determination of the working length, interappointment disinfection, and radiological control of the quality of obturation (1).

The success rate of root canal therapy reported in the literature is generally high, ranging from $85 \%$ to $95 \%(10-12)$. This variation is probably related to the lack of agreement among endodontists on a definition of success or failure of endodontic therapy (13). The success or failure of endodontic treatment should be clearly defined when there is an attempt to make assertions of the prognosis of root canal therapy. It is, however, desirable to apply widely accepted criteria for

Correspondence: Dr. Arnaldo de França Caldas Junior, Rua Amaro Gomes Poroca 225, Ap. 202, Cidade Universitária, $50741-530$ Recife, PE, Brasil.e-mail: caldasjr@elogica.com.br or arnaldocaldas@fop.upe.br 
the evaluation of the treatment outcome (14). Furthermore, there is a difference in the expertise of those who perform the treatment and the correct decision to treat or not to treat teeth with unfavorable prognosis.

A number of studies have retrospectively evaluated the success rate of endodontic treatment. However, few have been established to determine the outcome identifying factors that might influence the prognosis. Thus, the purpose of this research was to evaluate the biological, behavioral, clinical, radiographic and socioeconomic-demographic aspects of a cohort of patients treated at the Faculty of Dentistry, University of Pernambuco, Brazil.

\section{MATERIAL AND METHODS}

A retrospective cohort study was carried out evaluating patients who were submitted to endodontic therapy in 1998 and 1999 by students of the Faculty of Dentistry, University of Pernambuco. Recife is the state capital of Pernambuco, Northeast of Brazil, with an estimated population of $1,600,000$, mainly from low socioeconomic background. The average per capita family wage is US\$180 per month and $43.6 \%$ of the population receives less than US\$60 monthly according to government statistics (http://www.ibge.gov.br).

Endodontic treatment in Recife is largely provided by private practice or at dental faculties, since only a small number of dentists specialized in endodontics are employed by the dental public services.

The dental records of the sample were obtained from the endodontic clinic and comprised all patients treated in 1998 and 1999. Letters were sent to the patients informing them about the proposed survey and suggesting an appointment date for post-treatment control.

The next step was to select the ideal criteria to establish the success rate. For this reason, a broad review of the literature (332 articles from 1952 to 2002) was performed to identify the variables that were most often referred to in the literature. The selected variables were biological (type of tooth, health conditions, pulp and periapical pathology), clinical (DMF-T, pain, tooth mobility, intra- or extra-oral fistula, periodontal pocket, dental caries, swelling, presence of restoration or temporary restoration, tooth fracture, technical preparation of root canal, number of sessions, intracanal medicament, operatory accidents), radiographic (apical limit of filling, quality of root canal filling and presence of periapical rarefaction prior to or after treatment), socioeconomic-demographic and behavioral (gender, age, socioeconomic class, number of toothbrushings, selfreported oral health and last dental visit). In the present study, the authors chose to present the results, which were significant, by means of a logistical regression analysis.

Clinical success was indicated by the absence of signs and symptoms and it was assumed that the clinical success may have a strong relationship with the radiographic success determined by the following criteria: 1) no periapical lesion or lesion in progress present at the time of obturation; 2) periapical lesion present at time of obturation disappeared completely or was noticeably diminished in size.

The sample comprised 524 patients, both genders, ranging from 11 to 78 years of age. Patients were recalled after a period of 2 to 3 years for clinical and radiographic control. Trials were standardized and all necessary care was taken for data (training and calibration) and a pilot study of 50 cases was carried out to determine the feasibility of the proposed study.

Informed consent was obtained from each participant after providing the necessary information on the study design and objectives.

Participants were assigned to three socioeconomic categories: a) family income less than 2 times the minimum salary, b) earnings between 3 or more minimum salaries and c) earnings less than the minimum salary or those who did not have a steady formal job. This was adopted based on the Brazilian income distribution.

Those who agreed to participate were examined to assess all clinical and radiographic variables. An interview was carried out to collect information regarding age, gender, socioeconomic class and behavioral aspects.

The Statistical Program of Social Science (SPSS) was used for calculating frequency distributions, means and medians. Chi-square and Fisher's exact tests were used to calculate significance with the level of significance set at 5\%. Logistic regression models were used to confirm significant effect of several variables on endodontic treatment outcome.

\section{RESULTS}

The response rate was $78.2 \%$. The final sample size comprised $311(75.9 \%)$ women and 99 (21.1\%) men, age range 11 to 78 years. The mean age of partici- 
pants was 35.54 years. The sample contained a higher percentage of people who had not completed secondary school (59.1\%). Table 1 presents data on socioeconomic-demographic characteristics of the sample.

Table 2 shows the quality of endodontic treatment according to year of treatment. The majority of cases were considered successful (82.9\%), 3.2\% were doubtful and the percent distribution was very similar between the 2 years of treatment. Thus, there was no statistical difference between years, but when the rate of success/failure in each year was analyzed, the success rate was statistically significant compared to the failure rate.

In order to compare the quality of endodontic treatment with the biological, clinical, radiographic, socioeconomic-demographic and behavioral variables, the doubtful category was excluded from the analysis due to the small number of occurrences. Thus, a logistic regression model was performed with all variables that were statistically significant with the bivariate analysis, in order to establish the most important predictor variables for quality assessment.

Success was less frequent in patients with only up to primary school education (55.6\%) than those with a higher degree of education (89.7\%). The percentage of success was $6.9 \%$ higher in females compared with males $(87.3 \%$ vs $80.4 \%)$ although the difference was not statistically significant. The rate of success/failure between genders was similar in this study. The vitality

Table 1. Socioeconomic and demographic characteristics of the studied sample.

\begin{tabular}{lrc}
\hline Variable & $\mathrm{N}$ & $\%$ \\
\hline Marital status & & \\
$\quad$ Married & 251 & 61.2 \\
$\quad$ Single, divorced and widow & 159 & 38.8 \\
$\quad$ Total & 410 & 100 \\
Income (minimum salary) & & \\
$\quad$ Without job/income & 24 & 5.8 \\
Up to two & 63 & 78.8 \\
Three or more & 410 & 15.4 \\
Total & & 100 \\
Level of education & 19 & 4.6 \\
$\quad$ Up to primary level & 234 & 57.1 \\
$\quad$ Less than secondary level & 157 & 38.3 \\
Secondary level or more & 410 & 100 \\
$\quad$ Total & & \\
\hline
\end{tabular}

of the pulp showed a statistically significant relationship with the success of endodontic therapy $(p<0.05)$.

\section{DISCUSSION}

In the present study, there was a loss of $21.8 \%$ of the baseline sample. Some of these cases may have been due to failure and the patients did not return because the tooth or teeth had been extracted. Also, patients with successful treatment and symptomless teeth are less likely to make the effort to return. It is accepted in the literature that if the proportion of losses is large (range of $30-40 \%$ ), this would certainly raise serious doubts about the validity of the study results (15).

A fairly consistent rate of success was recorded for all teeth observed in this study. The overall success rate of $82.9 \%$ seen in this study was excellent, keeping in mind that treatment was carried out by dental students. It is difficult to compare the results of the present study with others in the literature because of the varied criteria used. The overall success rate described in a similar study was $76.1 \%$ and dental students also performed the root canal therapy (16). The results of this cohort study appear to be similar to others carried out under dental school conditions. Furthermore, endodontic treatment performed at dental schools and by practitioners engaged in endodontics tends to have higher success rates than treatment performed outside institutions for the general population (17).

The initial size of the periapical lesion influenced the outcome of treatment in this study. As shown in Table 3, the vitality of the pulp was a good predictor of successful therapy, as well as teeth presenting necro-

Table 2. Evaluation of quality of endodontic treatment according with year of treatment.

\begin{tabular}{|c|c|c|c|c|c|c|c|}
\hline & \multicolumn{2}{|c|}{1998} & \multicolumn{2}{|c|}{1999} & \multicolumn{2}{|c|}{ Both years } & \multirow[t]{2}{*}{ Pvalue } \\
\hline & $\mathrm{N}$ & $\%$ & $\mathrm{~N}$ & $\%$ & $\mathrm{~N}$ & $\%$ & \\
\hline Success & 188 & 83.6 & 152 & 82.2 & 340 & 82.9 & $\mathrm{p}>0.05$ \\
\hline Failure & 31 & 13.8 & 26 & 14.0 & 57 & 13.9 & \\
\hline Doubtful & 6 & 2.7 & 7 & 3.8 & 13 & 3.2 & \\
\hline Total & 225 & 100 & 185 & 100 & 410 & 100 & \\
\hline $\begin{array}{l}\text { P value } \\
\text { per year }\end{array}$ & \multicolumn{2}{|c|}{$\mathrm{p}<0.001$} & \multicolumn{2}{|c|}{$\mathrm{p}<0.001$} & & & \\
\hline
\end{tabular}


sis without periapical lesion. The current literature has suggested that the prognosis for successful repair decreases as the periapical area of rarefaction increases (12). When necessary, treatment should begin as soon as possible to minimize potential enlargement of the area of pathosis. Nevertheless, the early diagnosis of periapical pathosis in the public health system in Recife is a very difficult task. X-ray equipment available in public dental centers is still much behind the public demand and when the patient presents pulp pain, the treatment of choice for the dentist and the patient is normally tooth extraction. Restorative and endodontic treatment in Brazil is very expensive and mainly provided by the private sector. It is estimated that $70 \%$ of the time and money spent on dental care is in the private sector. Also, $67 \%$ of the total population has limited access to the dental care system. The number of tooth extractions in the adult population in Recife is still very high. A previous study in Recife, about the reasons for tooth extraction, showed that caries and sequelae were the main reasons for extraction (18).

The success-failure rate of endodontic treatment is dependent not only on the given circumstances at the beginning of treatment but also upon the treatment itself. In the present study, pulp vitality in the logistic

Table 3. Results of logistic regression for the total group of patients.

\begin{tabular}{lcc}
\hline Selected variables & Odds ratio & Significance \\
\hline Gender & 0.656 & $\mathrm{NS}$ \\
Level of education & & $\mathrm{p}<0.05$ \\
$\quad$ Up to primary level & 1.09 & $\mathrm{NS}$ \\
$\quad$ Secondary level or more & 2.38 & $\mathrm{p}<0.05$ \\
Treatment & & $\mathrm{p}<0.05$ \\
$\quad$ Vital pulp & 3.66 & $\mathrm{p}<0.05$ \\
$\quad$ Non-vital pulp & 3.14 & $\mathrm{p}<0.05$ \\
$\quad$ without periapical lesion & & \\
Retreatment & 0.38 & $\mathrm{NS}$ \\
Mobility & 0.23 & $\mathrm{p}<0.05$ \\
Technique of root preparation & & $\mathrm{p}<0.05$ \\
$\quad$ Anatomic & 0.13 & $\mathrm{p}<0.01$ \\
$\quad$ Dynamic & 0.98 & $\mathrm{NS}$ \\
Number of visits & & $\mathrm{NS}$ \\
$\quad$ One & 0.35 & $\mathrm{NS}$ \\
$\quad$ Two & 0.98 & $\mathrm{NS}$ \\
$\quad$ Three & 0.28 & $\mathrm{NS}$ \\
Operatory accidents & 0.51 & $\mathrm{NS}$ \\
& & \\
\hline
\end{tabular}

NS: not significant regression model presented an odds ratio of 3.66, meaning that the prognosis of successful root canal therapy in a vital tooth is 3 times higher than in the case of necrosis. Furthermore, when the anatomic root instrumentation technique was performed, the percentage of success increased $(p<0.01)$.

In general, measures of socioeconomic status are meant to provide information about an individual's access to social and economic resources. In practice, numerous indicators fit this description. Among the most commonly used are education and occupation. Less commonly used, but potentially as important, are economic measures such as income, the wage rate and wealth. Years of completed schooling are reported with reasonable ease and reliability and are a meaningful indicator of socioeconomic status for virtually all adults (19). These factors led to the selection of level of education and income in this study. The present findings showed no statistical difference between the quality of endodontic treatment and income; however, this result must be interpreted with caution. This finding may be related to the fact that the income profile of the population showed no differences in the group. In relation to the level of education, those individuals who had completed secondary schooling had a higher percentage of successful endodontic treatment $(p<0.05)$. The literature reports that the link between socioeconomic status and health must arise from one or both of the following: poor health can lead to low socioeconomic status and low socioeconomic status can lead to adverse health outcome (19). Furthermore, a lack of educational qualification is strongly associated with higher levels of disease (20).

Although there is controversy in defining the factors influencing the success of root canal therapy, four variables in this study were good predictors for successful therapy: the level of education of the sample, pulp vitality, the periapical status prior to treatment and the technique of root preparation.

In conclusion, these results suggest that it is possible to attain very high success rates for endodontic treatment when both the intraradicular and the extraradicular causes of failure of endodontic treatment are well managed.

\section{RESUMO}

Um estudo de coorte retrospectivo foi realizado com o intuito de avaliar o grau de sucesso dos tratamentos endodônticos realizados 
na Faculdade de Odontologia da Universidade de Pernambuco, Brasil. Os prontuários foram obtidos de todos os pacientes atendidos em 1998 e 1999. Os exames foram padronizados e um estudo piloto foi desenvolvido para determinar a confiabilidade do estudo proposto. O teste Qui-Quadrado e o Exato de Fisher's foram usados para calcular o nível de significância que foi previamente estabelecido em 5\%. O modelo de regressão logística foi utilizado para confirmar o efeito de algumas variáveis sobre a terapia endodôntica. O tamanho da amostra final foi de 311 $(75,9 \%)$ de mulheres e $99(21,1 \%)$ de homens. A maioria dos casos $(82,9 \%)$ foi considerada sucesso. O sucesso foi menos frequente nos pacientes com até educação infantil incompleta $(55,6 \%)$ do que aqueles com maior grau de instrução $(89,7 \%)$. Os tratamentos realizados em dentes portadores de polpa viva determinaram os melhores resultados com diferença estatística significativa $(\mathrm{p}<0,05)$. Esses resultados sugerem que é possível se obter um alto grau de sucesso do tratamento endodôntico quando as causas de insucesso intra e extraradicular são bem controladas.

\section{REFERENCES}

1. European Society of Endodontology. Consensus report of the European Society of Endodontology on quality guidelines for endodontic treatment. Int Endod J 1994;27:115-124.

2. Ray HA, Trope M. Periapical status of endodontically treated teeth in relation to the technical quality of the root filling and the coronal restoration. Int Endod J 1995;28:12-18.

3. Madison S, Wilcox LR. An evaluation of coronal microleakage in endodontically treated teeth. Part III. In vivo study. J Endod 1988;14:455-458.

4. Sundqvist G, Figdor D, Persson S, Sjögren U. Microbiologic analysis of teeth with failed endodontic treatment and the outcome of conservative re-treatment. Oral Surg Oral Med Oral Pathol 1998;85:86-93.

5. Seltzer S. Long-term radiographic and histological observations of endodontically treated teeth. J Endodon 1999;25:818-822.

6. Chugal N, Clive JM, Spångberg LSW. Endodontic infection: Some biologic and treatment factors associated with outcome. J Dent Res 2002;81:A410.

7. Souza RA. Clinical and radiographic evaluation of the relation between the apical limit of root canal filling and success in endodontics. Part 1. Braz Endod J 1998;3:43-48.

8. Travassos RMC, Caldas Jr AF, Albuquerque DS. Relationship between dental caries and the success of endodontic treatment. J Dent Res 2002;81:182.

9. Helminen SE, Vehkalahti M, Kerosuo E, Murtomaa H. Quality evaluation of process of root canal treatments performed on young adults in Finnish public oral health service. J Dent 2000;28:227232.

10. Kvist T, Reit C. Results of endodontic retreatment: a randomized clinical study comparing surgical and nonsurgical procedures. J Endodon 1999;25:814-817.

11. Testori T, Capelli M, Milani S. Success and failure in periapical surgery. A longitudinal retrospective analysis. Oral Surg Oral Med Oral Pathol 1999;4:493-498.

12. Ricucci D, Gröndahl K, Bergenholk G. Periapical status of rootfilled teeth exposed to the oral environment by loss of restoration or caries. Oral Surg Oral Med Oral Pathol 2000;90:354-359.

13. Harty FJ, Parkins BJ, Wengraf AM. The success rate of apicectomy. A retrospective study of 1016 cases. Br Dent J 1970;129:407-413.

14. Weiger R, Hitzler S, Hermle G. Periapical status, quality of root canal fillings and estimated endodontic treatment needs in an urban German population. Endod Dent Traumatol 1997;13:6974.

15. Hennekens CH, Buring JE. Epidemiology in Medicine. $1^{\text {st }}$ ed. Boston: Little, Brown and Co. 1987;153-177.

16. Tjäderhane LS, Pajari UH, Ahola RH, Backman TK, Hietala EL, Larmas MA. Leaving the pulp chamber open for drainage has no effect on the complications of root canal therapy. Int Endod J 1995;28:82-85.

17. Friedman S, Löst C, Zarrabian M, Trope M. Evaluation of success and failure after endodontic therapy using a glass ionomer cement sealer. J Endodon 1995;21:384_390.

18. Caldas Jr AF, Marcenes W, Sheiham A. Reasons for tooth extraction in a Brazilian population. Int Dent J 2000;50:267-273.

19. Meara E. Why is health related to socioeconomic status? The case of pregnancy and low birth weight. NBER Working Paper 2001; n. 8231 .

20. Whittle JG, Davies KW. A classification of residential neighbourhoods (ACORN) in relation to dental health and dental health behaviours. Community Dental Health 1992;9:217-224.

Accepted February 19, 2003 